Editorial

\title{
Looking Ahead in Games Research: Entry Points into a Pragmatic Field of Inquiry
}

\author{
Marko Siitonen ${ }^{1, *}$, Teresa de la Hera ${ }^{2}$ and Felix Reer $^{3}$ \\ ${ }^{1}$ Department of Language and Communication Studies, University of Jyväskylä, 40014 Jyväskylä, Finland; \\ E-Mail: marko.siitonen@jyu.fi \\ 2 Department of Media and Communication, Erasmus University Rotterdam, 3000DR Rotterdam, The Netherlands; \\ E-Mail: delahera@eshcc.eur.nl \\ ${ }^{3}$ Department of Communication, University of Muenster, 48143 Muenster, Germany; E-Mail: felix.reer@uni-muenster.de \\ * Corresponding author
}

Submitted: 26 September 2020 | Published: 6 January 2021

\begin{abstract}
This thematic issue presents a number of emerging scholarships into the study of digital gaming. The articles are based on a 2019 symposium on game studies hosted by the Digital Games Research section of ECREA. As the phenomena related to digital gaming keep on evolving and emerging, so must research keep up with the times and constantly challenge itself. Whether speaking about validating previously developed research methods, imagining totally new ones, or even challenging the whole philosophy of science on which research is being done, there is a constant need for reappraisal and introspection within games research. As a cultural medium that has become deeply embedded into the social fabric of the 2020 s, digital gaming continues to excite and challenge academia. This thematic issue provides a collection of approaches to look into the future that addresses some of the challenges associated with game research.
\end{abstract}

\section{Keywords}

digital games; game studies; methodology; serious games

\section{Issue}

This editorial is part of the issue "Games and Communication-Quo Vadis?" edited by Marko Siitonen (University of Jyväskylä, Finland), Felix Reer (University of Muenster, Germany) and Teresa de la Hera (Erasmus University Rotterdam, The Netherlands).

(C) 2021 by the authors; licensee Cogitatio (Lisbon, Portugal). This article is licensed under a Creative Commons Attribution 4.0 International License (CC BY).

\section{Introduction}

This thematic issue is built on a foundation laid down at a symposium organized by the Digital Games Research section of the European Communication Research and Education Association (ECREA) in 2019. The symposium, titled "Games, Media and Communication: Quo Vadis, Game Studies?," aimed at presenting both new scholarship within the interdisciplinary field of game studies, as well as pondering on research-related challenges and possibilities on the horizon.

Within media and communication studies, game studies represents a small but vibrant niche. In addition to ECREA, academic associations related to the field of communication research, such as the International Communication Association (ICA) and the US-based National Communication Association (NCA) have their own game studies sections, and we also know that communication researchers make up a large portion of the scholars doing games research in the first place (Quandt et al., 2015).

Despite being a young discipline, game studies has become an established field of research with its own methods, theory and, terminology (Mäyrä, 2008). Game studies, especially in the sense which we see it manifest within communication studies, represents in many ways a pragmatic field of inquiry. The phenomena it aims to understand are constantly changing and evolv- 
ing, and researchers have widely adopted approaches where theoretical and methodological frameworks are 'borrowed' across what might once have been disciplinary boundaries. Even though actual mixed-methods research is quite rare, on the whole methodological plurality is prevalent, as anyone attending a game studies conference (or reading this thematic issue!) can attest. Naturally, this state of affairs leads to a heterogeneous field with multiple methodological entry points. The articles included in this thematic issue are no exception to this rule. Next, we will provide a brief overview of each of them.

\section{Articles Included in the Thematic Issue}

In the first article of this thematic issue, Wehden, Reer, Janzik, Tang, and Quandt's (2021) study looks at how gaming experience may be influenced by using an omnidirectional virtual reality treadmill. The study sets out to test established concepts like 'flow' (Csíkszentmihályi, 1990), 'presence' (e.g., Steuer, 1992), and 'cybersickness' (e.g., McCauley \& Sharkey, 1992). The findings illustrate that even when new forms of gaming may be believed to solve existing problems (such as cybersickness here), they do not necessarily deliver on those promises. However, by connecting the concept of more natural locomotion in VR to a genre such as exergaming, it is possible to imagine new opportunities and directions for games' development and use. From a methodological viewpoint, Wehden et al.'s (2021) work also allows for us to consider an old question related to experimental design: How can we try to make sure that our carefully designed and controlled experiment is still close enough to actual lived reality? What kind of stimulus material and setup should we use, and how can we take into account issues such as possible novelty effects? As new gaming-related technologies continue to be introduced, the need for pushing boundaries also in research will remain a key challenge into the 2020s.

Keeping with the overall theme of experiments but taking a distinctly qualitative approach, Wilhelmsson, Susi, and Torstensson's (2021) article explores the benefits of combining elements of digital gaming with elements of analog games in the serious game Hidden in the Park. In the game, players are exposed to authentic online offender sexual grooming behaviors and are faced with the negative consequences of some of online information sharing. In their article the authors discuss how analog components can add an extra dimension to serious digital gaming experiences. In this case, the analog components allow for face to face social dynamics that contribute to the processing of the gaming experience, while the digital components provide an environment that is similar to the one that players are expected to reflect about and learn from. From a methodological perspective, this study required a synchronization of analog and digital components for which an activity system model that allowed both conceptualization and visualiza- tion of the game concept was used. This activity system became not only a valuable tool for communication within the design team, but also proved to be useful for the analysis of the effects and consequences of changes.

From a concrete viewpoint to developing so-called serious games, Jacobs' (2021) piece takes us to a more theoretically oriented pondering that sets out to explore avenues for research. Jacobs (2021) argues that even though the results of studies on the effects of serious games are quite promising, knowledge on their acceptance and adoption is still limited. Three different theoretical perspectives on player choice are outlined that can serve as starting points for future research: First, serious games can be understood as a form of promotional communication; second, playing serious games is a form of media experience; and third, serious games can be seen as technical innovations. Jacobs (2021) describes the implications of these three perspectives and discusses how knowledge from different research fields (like technology acceptance research or media psychology) may be fruitfully applied to serious games. The article concludes with methodological considerations on how these different theoretical viewpoints may be brought together in future empirical research.

In addition to educational settings, healthcare is often presented as one of the contexts where games and playful activities in general hold promise. De la Hera and Sanz (2021) present a timely example of how digital play may tie in with different phases of cancer treatment. Focusing especially on so-called unstructured free play, they illustrate the many ways in which young cancer patients may benefit from access to digital games, ranging from easing the difficulties related to isolation to benefits related to creating and maintaining social relations during the long treatment periods. Whether talking about playfully interacting with available technologies or drawing strength from identifying with game characters, the participants' experiences and perceptions speak volumes about the potential of play and games as coping strategies.

The idea that digital games can offer more than fun and can be meaningful to their users also plays a central role in the contribution by Daneels et al. (2021). Recent research has shown that games can provide eudaimonic experiences, such as feeling emotionally touched or gaining insights into purpose-in-life questions (Oliver et al., 2016). Against this background, Daneels et al. (2021) choose an innovative methodological approach by conducting a qualitative game experience analysis of the games Assassin's Creed Odyssey, Detroit: Become Human, and God of War. The results suggest that narrative elements and involvement with the characters evoke eudaimonic experiences. Further, these effects were found to be amplified by supporting game mechanics, like realistic graphics, the camera perspective, or ingame choices. The central findings of the study are visualized in an integrated model of eudaimonic game experiences that may serve as a basis for future research. 
Moving on from game experiences to the broader societal context surrounding digital gaming, Meriläinen (2021) presents the results of a qualitative study exploring Finnish teenagers' and parents' views of gamingrelated parenting practices. The study reveals the tensions that lie between intentions of protection and understanding, and the fact that participants' attitudes are not static but change depending on concrete families' circumstances. Young game players' perceptions analysis also shows that minors not only expect understanding, but also clear limits and guidance. The identification of this dichotomy is interpreted by the author as a clear need from young players to get the support from their parents to gain autonomy and agency. From a methodological perspective, the author highlights that the differences in perceptions identified in relation to different individual circumstances ask for a qualitative approach for a better understanding of gaming practices and interpretation of these practices.

Gekker (2021) closes the issue with "Against Game Studies," a thought-provoking piece of methodological exploration. The article offers a reading of the historical roots of game studies, and critiques the ways in which some of its typical characteristics may limit research. Gekker (2021) takes a strong stance in favor of adapting methodologies coming outside of the "core" of game studies, and imagines a new way forward that would center on play rather than games. This polemic piece evoked quite strong reactions from the three reviewers that read it, and it is our hope that it does exactly that within the broader readership as well. Being able to write a piece like this in the first place means that game studies as a field has a history, which we at least want to emphasize as a positive sign. Being able to look back opens up new doors into imagining a future for the field, and we quite simply need think-pieces such as this one to keep on advancing the field and exploring its boundaries.

\section{Looking Ahead}

The articles presented within this thematic issue, as well as the presentations during the symposium that spawned it, point to at least a couple of tendencies and central questions for game studies for the years to come.

A clear evolution in the field of game studies is the growing attention to play over (and/or on top of) just games. Some scholars are moving their attention from game studies to play studies. "Games don't matter," defends Sicart (2014, p. 2), "like in the old fable, we are fools looking at the finder when someone points at the moon. Games are the finger; play is the moon" (p. 2). This tendency can be seen in the contributions of some scholars to this issue (i.e., the pieces of de la Hera \& Sanz, 2021; or Gekker, 2021).

Another topic of continuous attention is the question of methodologies. It has been argued that the particular characteristics of games that differentiate them from other media objects ask for more sophisticated method- ologies that allow a systematic analysis of games and the discourses embedded and surrounding gaming practices (Fernández-Vara, 2014). We are confident that scholars interested in digital gaming will continue to explore new avenues in this regard, and tackle the challenges of the ever-changing phenomenon they are trying to understand. In many cases, this will mean continuing in multidisciplinary pathways and in what one could even characterize as following a philosophy of pragmatism.

The long game (pun intended) deals with slowly developing what could be called a paradigm or paradigms of research in game studies. Exploring "shared beliefs within a community of researchers who share a consensus about which questions are most meaningful and which methods are most appropriate for answering those questions" (Morgan, 2007, p. 53) is key in making sense not only of the phenomena we are trying to understand, but also of ourselves as researchers and academics. As a (relatively) young field, games research is in a good place when it comes to pondering philosophy of science: Not too old to suffer from the heavy burden of history, but old enough to have a heritage to draw on.

It is our hope as editors of this thematic issue, that the studies within motivates the reader to be bold in trying out new approaches and methodologies, as well as challenging existing assumptions on "how things are done" within game studies.

\section{Conflict of Interests}

The authors declare no conflict of interests.

\section{References}

Csíkszentmihályi, M. (1990). Flow: The psychology of optimal experience. New York: Harper.

Daneels, R., Malliet, S., Geerts, L., Denayer, N., Walrave, M., \& Vandebosch, H. (2021). Assassins, gods, and androids: How narratives and game mechanics shape eudaimonic game experiences. Media and Communication, 9(1), 49-61.

de la Hera, T., \& Sanz, C. S. (2021). The role of spontaneous digital play during young patients' cancer treatment. Media and Communication, 9(1), 39-48.

Fernández-Vara, C. (2014). Introduction to game analysis. New York, NY: Routledge.

Gekker, A. (2021). Against game studies. Media and Communication, 9(1), 73-83.

Jacobs, R. S. (2021). Winning over the players: Investigating the motivations to play and acceptance of serious games. Media and Communication, 9(1), 28-38.

Mäyrä, F. (2008). An introduction to game studies: Games in culture. London: Sage.

McCauley, M. E., \& Sharkey, T. J. (1992). Cybersickness: Perception of self-motion in virtual environments. Presence: Teleoperators and Virtual Environments, 1(3), 311-318.

Meriläinen, M. (2021). Crooked views and relaxed rules: 
How teenage boys experience parents' handling of digital gaming. Media and Communication, 9(1), 62-72.

Morgan, D. L. (2007). Paradigms lost and pragmatism regained: Methodological implications of combining qualitative and quantitative methods. Journal of Mixed Methods Research, 1(1), 48-76. https://doi. org/10.1177/2345678906292462

Oliver, M., Bowman, N., Woolley, J., Rogers, R., Sherrick, B., \& Chung, M.-Y. (2016). Video games as meaningful entertainment experiences. Psychology of Popular Media Culture, 5(4), 390-405.

Quandt, T., Van Looy, J., Vogelgesang, J., Elson, M., Ivory, J. D., Consalvo, M., \& Mäyrä, F. (2015). Digital games research: A survey study on an emerging field and its prevalent debates. Journal of Communication, 65(6),
975-996. https://doi.org/10.1111/jcom.12182

Sicart, M. (2014). Play matters. Cambridge, MA: The MIT Press.

Steuer, J. (1992). Defining virtual reality: Dimensions determining telepresence. Journal of Communication, 42(4), 73-93.

Wehden, L.-O., Reer, F., Janzik, R., Tang, W. Y., \& Quandt, T. (2021). The slippery path to total presence: How omnidirectional virtual reality treadmills influence the gaming experience. Media and Communication, 9(1), 5-16.

Wilhelmsson, U., Susi, T., \& Torstensson, N. (2021). Merging the analogue and the digital: Combining opposite activities in a mixed media game. Media and Communication, 9(1), 17-27.

\section{About the Authors}
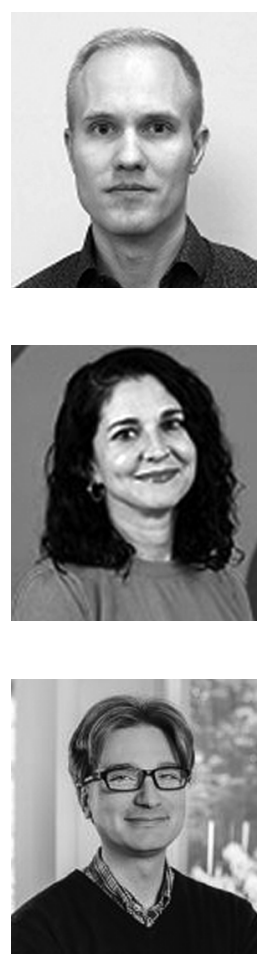

Marko Siitonen (PhD) works as an Associate Professor at the Department of Language and Communication Studies, University of Jyväskylä, Finland. His research has focused on social interaction in gaming communities across contexts. In addition, his research interests span the topical areas of intercultural communication and technology-mediated communication at work. He is the Chairperson of the ECREA Digital Games Research section, as well as the Finnish Society for Game Research.

Teresa de la Hera is Assistant Professor in Persuasive Gaming at Erasmus University Rotterdam, in the Netherlands, where she is a member of the Gaming Matters Research Cluster. Her expertise is in the study of the use of games and play to positively change players' attitudes and behaviors. She is the Author of the book Digital Gaming and the Advertising Landscape (2019) and the main Editor of the edited volume Persuasive Gaming in Context (2020), both published by Amsterdam University Press.

Felix Reer is a Postdoctoral Researcher in the Department of Communication at the University of Muenster, Germany. His research interests include social media and online communication, effects of digital games, and the use of highly immersive media technologies, such as virtual reality and augmented reality devices. He is Vice-Chair of the Digital Games Research Section of the European Communication Research and Education Association (ECREA). 